\title{
Tradições culturais no ensino de música em classes hospitalares
}

\author{
Rita de Cássia Silva Cardoso ${ }^{1}$ \\ Eudes Oliveira Cunha² \\ Ângelo Tavares Castro 3 \\ Submetido em 28/02/2021 \\ Aprovado em: 25/04/2021
}

DOI: $10.5965 / 2358092525252021090$

1. Mestra em Artes pela Universidade Federal da Bahia (Prof-Artes/UFBA) e professora da Rede Municipal de Ensino de Salvador.E-mail: cassicas@gmail.com.

2. Doutor em Educação. Professor do Instituto Federal Baiano (IF Baiano) e da Rede Municipal de Ensino de Salvador. Docente colaborador do Mestrado Profissional em Artes da Universidade Federal da Bahia (Prof-Artes/UFBA). E-mail: eudesocunha@gmail.com.

3. Doutor em Composição. Professor do Instituto de Humanidades Artes e Ciências Professor Milton Santos da Universidade Federal da Bahia. Docente vinculado ao Mestrado Profissional em Artes da UFBA (Prof-Artes/UFBA). E-mail: antares@ufba.br. 


\section{RESUMO}

Este trabalho tem o objetivo de descrever práticas de ensino de Música em classes hospitalares, a partir de uma proposta que se baseou em saberes musicais da tradição oral do Nordeste brasileiro. Ao considerar as especificidades da escolarização em ambiente hospitalar, elaborou-se um projeto de ensino de Música que integrou saberes oriundos das vivências dos discentes, associados aos conhecimentos definidos no currículo escolar. As reflexões apresentadas decorrem de experiências docentes em diálogo com compreensões no âmbito dos estudos teóricos sobre Educação Musical. Os resultados demonstraram intensa participação das crianças nas aulas de Música, cujos resultados indicam a importância do ensino de Música/Arte nas classes hospitalares, em especial, das expressões da cultura oral nos processos de ensino e aprendizagem. Propõe-se caminhos metodológicos que poderão contribuir para a formação de profissionais que tenham interesse em atuar nessa modalidade educacional.

Palavras-chave: ensino de música, classe hospitalar, tradições culturais. 


\section{ABSTRACT}

This work aims to describe music teaching practices in hospital classes based on a proposal sustained by oral tradition knowledge from Northeastern Brazil. When considering the specificities of schooling in a hospital environment, a Music teaching project was developed integrating knowledge from student's experiences and associating it with the one defined in the school curriculum. The reflections presented are the result of teaching experiences in dialogue with understandings within the scope of theoretical studies on Music Education. The results has revealed an intense participation of children in Music classes, whose results indicates the importance of teaching Music / Art in hospital classes, especially the expressions of oral culture in the teaching and learning processes. Methodological paths are proposed that may contribute to the training of professionals who have interest working in this educational modality.

Keywords: music teaching, hospital classes, cultural traditions. 


\section{INTRODUÇÃO}

A educação em ambiente hospitalar constitui-se de diferentes abordagens, ora inspiradas nas políticas de humanização, caracterizadas por uma pedagogia própria do ambiente hospitalar, ora compreendidas como forma de garantir o direito à educação, previsto na legislação educacional brasileira.

$\mathrm{Na}$ perspectiva de Fonseca (2008), a peculiaridade da educação hospitalar é assegurar a manutenção dos vínculos escolares, devolver à criança a sua escola de origem sem maiores prejuízos pelo afastamento temporário. Dessa forma, as práticas pedagógicas no ambiente hospitalar têm evidenciado que esta modalidade é uma importante política de enfrentamento da exclusão escolar da criança doente. Há também o entendimento de que a prática do professor nesse ambiente, além de ajudar na reintegração dos discentes à sua escola de origem, ameniza a dor e a ansiedade de quem se encontra internado (FONSECA, 2008; RODRIGUES, 2012).

Em 2001, a Rede Municipal de Ensino de Salvador instituiu o seu programa de classes hospitalares ${ }^{4}$. Ao longo dos anos, a proposta foi aprimorada e, em 2015, criou-se uma escola com sede administrativa própria para a condução dos processos de gestão de cada classe que se distribuíram em 12 unidades hospitalares no referido município. Atualmente, a instituição - denominada "Escola Municipal Hospitalar e Domiciliar Irmã Dulce" ${ }^{5}$ - possui uma estrutura administrativa com direção, vice-direção, coordenação pedagógica e secretaria escolar.

\footnotetext{
4. Classe Hospitalar é a terminologia utilizada pelo Ministério da Educação (MEC) para designar o atendimento pedagógico educacional realizado em hospitais, com fins de continuidade do aprendizado de conteúdos curriculares.

5. Além dos hospitais, a Escola Municipal Hospitalar e Domiciliar tem classes distribuídas em quatro clínicas, duas Casas Lar, três casas de apoio e 20 domicílios residência. A equipe de docentes é composta por 35 professoras regentes de turma, distribuídas nas unidades, e quatro professores de música que atendem a maior parte destas unidades, em um formato de alternância (uma visita por semana em cada classe). A duração da aula depende do quadro clínico dos discentes, do local onde é ministrada (leito, espaço adaptado ou sala de aula), podendo ter em torno de 20 minutos até uma hora de duração.
} 
Ao considerar que a escola em ambiente hospitalar visa a oferta de atendimento educacional para estudantes em condições especiais de saúde, a Música nesse contexto torna-se uma aliada das práticas pedagógicas com fins de atender ao currículo escolar. Ademais, a área de Música integra o componente obrigatório Arte, conforme define a legislação educacional brasileira, e deve ser inserida nesta modalidade educacional que visa proporcionar escolarização para pessoas impedidas de frequentar a escola comum.

O professor de Música que atua em hospitais tem o desafio de desenvolver uma prática atenta às especificidades desse ambiente cujo cotidiano de trabalho distingue-se da escola regular. Há necessidade, por exemplo, de adequação do currículo, como também adaptações das metodologias de ensino de acordo com as condições de saúde/doença - que envolve um tempo pedagógico mediado por uma escuta atenta e sensível -, observação do quadro clínico. Dessa forma, é necessário pensar em outras formas de interação social nesse ambiente que historicamente é caracterizado pelos cuidados com a saúde.

No município de Salvador 6 , a experiência do ensino de Música nas classes hospitalares, desde 2008 tem possibilitado reflexões sobre a relação entre a educação escolar e suas interfaces com o campo da educação especial e pode trazer lições que contribuem para a formação de docentes na área de Arte/ Música. Nesse sentido, as demandas decorrentes da atuação de professores de Música nesta modalidade educacional levaram à elaboração de uma proposta de ensino voltada para os saberes das Tradições Culturais. Buscou-se, assim, atender às demandas dos discentes que em maioria são provenientes de diversas regiões da Bahia e trazem conhecimentos que são próprios da sua cultura, dos seus espaços escolares e familiares.

6. Este artigo apresenta as experiências vividas na proposta de intervenção desenvolvida no âmbito do Mestrado Profissional em Artes (Prof-Artes), na Universidade Federal da Bahia (UFBA), concluído em 2020. A autora deste trabalho atuou diretamente na execução da proposta elaborada durante seus estudos no referido curso. 
Portanto, a orientação da referida proposta partiu do pressuposto de que a escola é espaço de diálogo entre os saberes de onde emergem as identidades dos discentes e desvelam o seu lugar de pertencimento na interface com os saberes universais do currículo. Tal proposição emerge de um estudo desenvolvido nas classes hospitalares de Salvador, que teve o objetivo de compreender as Tradições Culturais do Nordeste como estratégia pedagógica nas aulas de Música em Hospitais, voltadas às crianças submetidas a Terapia Substitutiva Renal e Oncologia nas enfermarias do Hospital Geral Roberto Santos e Hospital Martagão Gesteira em Salvador. Ao compreender que a memória oral exerce significativa importância no processo de ensino e aprendizagem, propõe-se a utilização e valorização dessas memórias nas práticas de professores de Música que atuam neste espaço.

A metodologia que compreende este estudo é de natureza descritiva. Trata-se de um relato de experiência docente em que os dados emergem de observações assistemáticas em diálogo com a produção da pesquisa em educação musical. O trabalho foi conduzido em duas etapas, sendo a primeira voltada para os estudos teóricos sobre o ensino de Música em classes hospitalares; e a segunda, voltada à elaboração e execução da proposta de intervenção. A partir de vivências em sala de aula e de observações dos ambientes onde ocorreram a interação aluno-professor nos hospitais, buscou-se a compreensão da dinâmica dos espaços e o entendimento sobre as patologias e tratamentos de saúde do aluno(a). Tais conhecimentos orientaram a elaboração do planejamento das aulas e, principalmente, a elaboração das atividades e execução das estratégias de ensino que abordaram temáticas das Tradições Culturais do Nordeste brasileiro.

Na próxima seção, discorre-se sobre a concepção de tradições culturais que orientou a proposta de ensino. Na sequência, descreve-se as práticas docentes em Música que viabilizaram a inserção de manifestações culturais tradicionais do Nordeste brasileiro nas classes hospitalares. Por fim, são apresentadas as considerações finais. 


\section{TRADIÇÕES CULTURAIS}

A articulação entre os saberes formais da escola e aqueles oriundos das vivências dos alunos requer uma compreensão das concepções sobre tradições culturais e sua relevância para os processos de ensino e aprendizagem no contexto escolar. Na perspectiva de Jean Claude Forquin (1993, p. 24), existe uma relação íntima e orgânica entre educação e cultura. Há sempre a comunicação, a transmissão, a aquisição de conhecimentos: crenças, competências, hábitos e valores que constituem o seu conteúdo. Assim, a ideia de "[...] educar, ensinar, é colocar alguém em presença de certos elementos de cultura a fim de que este alguém deles se nutra, os incorpore à sua substância e construa sua identidade intelectual e pessoal em função deles [...]".

Considerando as variadas formas de pensar o conceito de cultura popular, Abreu (2003, p. 83) salienta:

Para uns, a cultura popular equivale ao folclore, entendido como o conjunto das tradições culturais de um país ou região; para outros, inversamente, o popular desapareceu na irresistível pressão da cultura de massa (sempre associada à expansão do rádio, televisão e cinema) e não é mais possível saber o que é originalmente ou essencialmente do povo e dos setores populares.

Dessa forma, dada a diversidade de sentidos e a complexidade no uso do termo cultura popular, para efeito deste trabaIho, adota-se a noção de Tradições Culturais para expressar as manifestações artístico-culturais presentes na memória oral do povo do Nordeste.

Conforme salienta Cascudo (2006, p. 27), “[...] entende-se por tradição, traditio, tradere, entregar, transmitir, passar adiante, o processo divulgativo do conhecimento popular ágrafo". O autor considera que a literatura oral brasileira é composta dos elementos trazidos das três raças - indígenas, portugueses e africanos - para a memória e uso do povo atual, e que as tradi- 
ções mantêm vivas as manifestações populares provenientes dos conhecimentos passados através da literatura oral.

Ainda de acordo com Cascudo (2004, p. 710), "[...] a cultura popular é o saldo da sabedoria oral na memória coletiva" e propõe:

\begin{abstract}
A Memória é a Imaginação do Povo, mantida comunicável pela Tradição, movimentando as Culturas, convergidas para o Uso, através do Tempo. Essas Culturas constituem quase a Civilização nos grupos humanos. Mas existe um patrimônio de observações que se tornam Normas. Normas fixadas no Costume, interpretando a Mentalidade popular". (CASCUDO, 2013, p. 11)
\end{abstract}

Dessa forma, deduz-se por tradição aquela informação que é passada de forma sucessiva de uns para os outros, através dos tempos, e que ficam conservadas na memória seguindo a linha da oralidade.

A formação de uma sociedade é constituída de histórias. São tradições que se perpetuam ao longo dos séculos, que expressam significados de determinados agrupamentos sociais, denotam valores morais e intelectuais e comportamentos. Elas se referem a uma herança cultural e nos conduz a pensar em crenças, práticas, valores, hábitos, rituais que contribuem para os processos educativos. Dessa forma, é importante a sua ressignificação e que não se percam com o passar do tempo para que outras gerações possam usufruir desses saberes que constituem nossas identidades.

À vista desses aspectos mencionados, a Escola pode ser considerada uma instituição socializadora, capaz de incorporar as múltiplas culturas em seu projeto pedagógico e tê-las como aliadas no processo de ensino e aprendizagem do aluno. Portanto, neste trabalho, conforme referido, recorreu-se a essa concepção de tradições culturais, presentes na memória oral do povo nordestino. 


\section{ENSINO DE MÚSICA EM HOSPITAIS DE SALVADOR}

As aulas de Música foram desenvolvidas em uma sala de aula que funciona dentro dos hospitais e em leitos. É um ambiente normalmente marcado pela doença: momentos de dor, incertezas e desconfortos muitas vezes próprios do tratamento. Como são provenientes de diferentes lugares e como a socialização entre esses alunos só acontece durante a internação, buscou-se valorizar a cultura que já possuíam, na tentativa de ampliar a convivência na diversidade, mas respeitando os seus valores étnicos e culturais.

Para o desenvolvimento do projeto, recorreu-se a expressões da nossa cultura, tais como: as paisagens sonoras de feiras e festas populares; as sonoridades dos cantos de trabalho e brincadeiras; manifestações culturais como a Folia de Reis, Congada, Capoeira, Samba de Roda, não deixando de citar as oriundas de outras regiões do Brasil, como, o Frevo, do Pernambuco, Tambor de Crioula do Maranhão, Reinado de Minas Gerais.

As Tradições Nordestinas são muito diversas em seus elementos: são cores, gostos, cantos, danças e ritmos que inspiram uma profusão de atividades criativas para aplicação nas classes hospitalares. E foi assim, pensando em levar para os leitos conteúdos que dialogassem com a cultura dos alunos, que foram selecionadas atividades que estivessem presentes no cotidiano do povo nordestino. Portanto, desenvolveram-se diversos temas, como: Feira, Farinhada, Cantos de Trabalho, Coco, Puxada de Rede e as Ganhadeiras de Itapuã. A maioria delas está associada às práticas laborais relacionadas às Tradições Nordestinas.

A seguir, descrevem-se duas delas: Farinhada e Ganhadeiras, as quais se consideram representar a identidade cultural das crianças, e que, de alguma forma, representam a realidade e expressam elementos da memória oral dos alunos da classe hospitalar de Salvador. 


\section{- Farinhada}

Esta manifestação é muito comum no Nordeste. Trata-se de uma prática coletiva de fazer farinhas seguindo as tradições das Casas de Farinha. Esta atividade é executada com cantorias, danças e festas que se estendem pela noite. Dessas casas saem vários alimentos, como, beiju, farinha, tapioca, carimã, polvilho, entre outros derivados da mandioca que são vendidos nas feiras livres.

Utilizou-se para esta atividade a música "Farinhada", de autoria do compositor Zé Dantas, conhecida na interpretação de Luiz Gonzaga. A letra da música faz menção à utilização da peneira, elemento central dessa atividade laboral. Com a música "Farinhada", trabalhou-se a melodia, o ritmo e a pausa. Fez-se uma audição voltada apenas para os instrumentos presentes na gravação, como identificar o triângulo, a zabumba e a sanfona. Após essa breve apreciação foram apresentados outros instrumentos como o ganzá, o caxixi, a clave e o triângulo. Depois de expor esses instrumentos in loco, deixou-se que escolhessem qual desejavam tocar.

Ao iniciar a audição, a professora de Música executou o ritmo utilizando um ganzá e pediu para que os discentes a acompanhassem. O ritmo dessa música, na versão de Luiz Gonzaga e Elba Ramalho, pode ser explorado nas aulas, principalmente pelas possibilidades de uso das pausas dos finais das estrofes, para realizar movimentos corporais, como abrir ou levantar os braços, podendo também fazer poses ou bater palmas nesses instantes de silêncio. Quando a música retorna ao ritmo normal, todos tendem a voltar acompanhando a sequência inicial. Essa atividade foi importante para eles perceberem as diferenças rítmicas, a pulsação da música e os instrumentos do forró. Além disso, esses foram momentos de descontração em que os discentes participavam de maneira divertida.

Observou-se que os estudantes mais novos tinham alguma dificuldade em identificar os instrumentos, porém a maioria conseguiu sentir a pulsação e o ritmo. Na prática, quando a aula acontece na enfermaria coletiva, propõe-se que se faça uma 
troca entre os participantes para que todos possam experimentar as diferenças físicas, sonoras e as várias formas de execução de cada instrumento.

Alguns alunos conhecem bem essa cultura, outros passaram a conhecê-la naquele momento. Nas enfermarias coletivas, com mais de um paciente, as conversas sobre os temas puderam ser proveitosas, principalmente com a participação dos acompanhantes. Dessa forma, quando essa interação aconteceu, foi possível perceber que aquele ambiente hospitalar, normalmente triste, transformava-se em um ambiente mais descontraído e divertido.

\section{- Ganhadeiras}

Outro tema desenvolvido teve enfoque na diáspora africana. Neste, o objetivo de ensinar conteúdos musicais de maneira contextualizada ao abordar o período histórico da época da escravidão, a partir dos sambas gravados pelas Ganhadeiras de Itapuã. Assim, buscou-se atividades que nos remetessem às formas de resistência e sobrevivência do povo negro em reposta àquele momento de violência e exclusão. De acordo com Prandi (2000, p. 58), “[...] com o fim da escravidão, a população negra, na tentativa de se integrar à sociedade brasileira, não como africanos, mas como brasileiros, teria se desinteressado de suas próprias origens". Dessa forma, Prandi (2000) afirma que a cultura africana foi se diluindo na formação da cultura nacional, criando assim uma identidade afro-brasileira. Na Bahia, ela se expressa de diversas formas, tanto na capital como em várias regiões no interior do Estado. Está presente na capoeira, no vestuário, na música, na dança, na gastronomia, na religião e entre tantas outras dimensões da vida, como na língua, por exemplo.

Itapuã é um bairro de Salvador cheio de histórias, poesia e resistência. Concentra uma grande população de negros descendentes de africanos escravizados. Muitos costumes e tradições ainda persistem no local e podem ser vistos no seu cotidiano, 
pois são resistentes e atuantes. A pesca e o trabalho de ganho7, por exemplo, são duas atividades laborais que fazem parte da cultura e da formação identitária dos "filhos de Itapuã". A Puxada de Rede e o Trabalho de Ganho são atividades que fazem parte da história de subsistência do negro naquele período.

Essa atividade teve o objetivo de observar, por meio da Música, o universo feminino mediante a manifestação das Ganhadeiras, como tem-se o exemplo das Baianas de Acarajé. A ideia foi apresentar para as crianças a labuta da mulher negra no trabalho de ganho. As ganhadeiras eram mulheres escravizadas ou libertas, que tinham como fonte de renda o ganho de rua.

Em Salvador, as Ganhadeiras vestiam roupas ao estilo dos antepassados, tais como: turbante na cabeça, saia rodada estampada, camisa de renda branca e colares de conchas. Algumas traziam seus filhos amarrados nas costas com "pano da costa"8 ou soltos, entre os tabuleiros, em meio a frutas e aves.

Vale ressaltar que foi no período colonial que o famoso acarajé começou a ser comercializado nas ruas de Salvador. Essa tradição se perpetuou nos tabuleiros das ganhadeiras e está presente até os dias de hoje, servindo como fonte de renda para várias mulheres afrodescendentes. E foi a partir da cultura do trabalho de ganho das mulheres negras de Itapuã, que, em 2004, surgiu o grupo musical Ganhadeiras de Itapuã, com o desejo de preservarem a memória cultural do bairro, sobretudo as ganhadeiras do fim do século XIX e início do século XX.

O grupo tem como sua principal forma de expressão a Música, com o repertório baseado em cantigas e samba de roda. No início das atividades do grupo, o samba de roda ganhou o título de Patrimônio Cultural do Brasil pelo Instituto do Patrimônio

\footnotetext{
7. Os trabalhadores de ganho, vistos em cidades brasileiras principalmente entre os séculos XVIII e XIX, eram negros africanos e de descendência africana, escravizados ou libertos, postos para trabalhar nas ruas, em atividades comumente desprezadas pela mão de obra branca e livre (LEAHY, R. (2017, p. 2).

8. O Pano da Costa faz parte do vestuário de mulheres africanas, sendo um acessório utilizado em diversos países do continente. É uma espécie de xale, usado de várias formas: sobre as costas; jogado no ombro; cruzados na frente; amarrados sobre o busto ou na cintura, como uma faixa estreita ou larga e numa espécie de avental (GASPAR, 2013).
} 
Histórico e Artístico Nacional (IPHAN). Um ano depois foi proclamado Obra-Prima do Patrimônio Oral e Material da Humanidade pela Unesco (OLIVEIRA, 2017).

Portanto, a partir do trabalho musical das Ganhadeiras, utilizou-se o samba de roda nas aulas de Música. Como os alunos hospitalizados em grande parte residiam no Recôncavo baiano, e possuíam o samba de roda como parte da sua formação cultural, este estilo rítmico, além de colaborar para o aprendizado sociocultural, possibilita a prática dos seus diversos aspectos e pode ser considerado como escola permanente da vida. Este gênero musical proporciona

[...] uma formação musical e estética abrangente e integrada organicamente nos processos do cotidiano que contempla as seguintes competências musicais: onomatopeia, timbres sonoros, ritmo (elementar e polirritmia), melodia, harmonia, diálogos musicais, improvisação, técnica instrumental e vocal, memória, prontidão, alternância, variações etc. (DÖRING, 2012, p. 9).

Dessa forma, para contar a história dessas "guerreiras", o Samba de Roda foi um elemento muito importante durante as aulas, pois ficou evidente a identificação de alguns alunos e seus acompanhantes com o estilo, o que se configurou numa aula alegre e movimentada.

Para ilustrar, utilizou-se fotos antigas das atividades das ganhadeiras, dos pescadores e das embarcações típicas do litoral nordestino utilizadas para pesca, como o saveiro e a jangada. A música para esta audição foi "As Ganhadeiras", de autoria de Lídio Brandão, gravada pelo grupo em 2014, no seu primeiro álbum. 


\section{As Ganhadeiras ${ }^{9}$}

As ganhadeiras nascidas na praia de Itapuã Vendendo peixinhos baratos, pescados pela manhã Quem quer comprar os peixinhos, eu trago aqui pra escolher Deus the ajude a pescar pra você vender Já vou embora senhores, espera até quando eu voltar Vou esperar a chegada do saverinho no canal E também as jangadinhas que andam no mar a navegar Com todos peixinhos que nós precisamos rematar

Essa música é um Samba de Roda com elementos marcantes para identificar: homens e mulheres vendendo comida, palmas e instrumentos de todos os naipes. Os discentes apreciaram a música ao tempo que eram conduzidos para uma escuta atenta, com informações sobre o estilo, interpretação e instrumentos musicais utilizados, bem como o autor, um senhor da comunidade que já havia falecido. Esses conhecimentos históricos descritos foram apresentados aos estudantes de maneira dialogada, em conversas informais, por meio da contação de histórias, ilustrações, fotografias e vídeos, de modo que pudessem ser mediados pela ludicidade tão necessária ao trabalho docente com crianças.

As duas atividades escritas consistiam em completar a letra da música. Foram aplicadas de acordo com o grau de escolaridade do aluno. Para as crianças não alfabetizadas, a atividade era ilustrada com números e as figuras que faziam parte do vocabulário da música: pescador, saveiro, baiana de acarajé (ganhadeira), jangada, praia e peixinhos. Os espaços em branco na letra eram relativos a essas figuras e eles precisam completar com o número certo de acordo com a ordem de aparição na melodia.

9. Composição: Lídio Brandão (Falecido) | Intérprete: Ganhadeiras de Itapuã. 
Para as crianças alfabetizadas, a atividade era dividida em duas partes: a primeira consistia em completar a letra da música à medida que fossem ouvindo, e a segunda, consistia em responder a um roteiro de apreciação. Este roteiro induzia as crianças a prestarem atenção nas vozes, nos instrumentos e nos timbres. Uma das estratégias utilizadas para esta escuta foi apresentar aos alunos, antes da audição, os naipes de corda, percussão e sopro com o uso de um aplicativo de celular. Dessa forma, no momento da apreciação, eles foram capazes de responder à atividade com menos dificuldades, conseguindo identificar os sons dos instrumentos à medida que escutavam a música. Para finalizar a atividade de escrita, a música foi novamente ouvida. Eles acompanhavam batendo palmas, como o fazem num encontro tradicional de samba de roda.

Do ponto de vista da educação musical, observou-se que os alunos conheceram as histórias do samba de roda e das Ganhadeiras de Itapuã, e puderam vivenciar conteúdos propriamente musicais durante o processo. Por meio da escuta atenta ao repertório trabalhado e das vivências nas aulas, puderam conhecer instrumentos musicais, reconhecer timbres, alturas e diferentes células rítmicas, bem como aprender letras de canções, tocar instrumentos e desenvolver atividades criativas no ambiente hospitalar.

Importante ressaltar que as atividades descritas neste trabaIho representam parte do trabalho desenvolvido ao longo do ano letivo. As propostas metodológicas seguiam uma sequência estrategicamente planejada para se chegar ao objetivo de aprendizagem. É relevante enfatizar que as aulas em hospitais devem ser planejadas de modo que o conteúdo seja finalizado a cada encontro, devido aos casos de alunos que têm período de curta permanência no hospital e podem ter alta médica, não tendo a oportunidade de outros encontros com o professor de Música. 


\section{CONSIDERAÇÕES FINAIS}

As aulas de Música em Hospitais demandam metodologias diversificadas para efetivação de uma educação inclusiva. Nesse sentido, a proposta de ensino descrita possibilitou vivências e reflexões sobre o uso das Tradições Culturais do Nordeste como estratégia pedagógica para a atuação de professores de Música em contextos hospitalares.

Optou-se por um olhar crítico sobre esse pluralismo para entender de que forma essas vivências socioculturais, trazidas pelos alunos e seus familiares, refletem no processo de aprendizagem nas classes hospitalares de Salvador e nas aulas de Música durante o tratamento de saúde.

Um dos desafios no Ensino de Música nesse ambiente é o de superar a ambiguidade que muitas vezes se manifesta quando a Música é compreendida no contexto hospitalar, ora como atividade-meio para fins voltados à Saúde, ora como prática educativa que proporciona formação em Artes. Nesse sentido, propõe-se, com as aulas de Música em hospitais, que a sua finalidade seja a da formação artística, com enfoque nos processos de aprendizagem por meio de vivências e de práticas lúdicas guiadas pelo prazer estético, mesmo em situações de adoecimento, como são os casos dos discentes das classes hospitalares.

Embora cuidar da saúde do aluno não seja exatamente o objetivo do professor de Música, durante as práticas foi observada a forte contribuição que as aulas de Música exercem sobre o aspecto emocional das crianças e adolescentes hospitalizados, sobretudo, trazendo para eles as tradições integradas às suas realidades, o que proporciona alegria, estimula a imaginação, a criatividade e a interação com o outro.

Esse ambiente de encontros, trocas e afetos foi determinante para a aproximação entre docente e alunos e proporcionou conhecimentos sobre suas tradições: as práticas puderam ressignificar a memória afetiva por meio dos sons, hábitos, cheiros, ritmos, canções e danças passadas de geração em geração por intermédio da oralidade. Sendo assim, as manifestações Farinhada e Ganhadeiras, descritas neste trabalho, foram algu- 
mas das atividades desenvolvidas que trouxeram esses olhares sobre as aulas de Música nas classes hospitalares de Salvador.

Sob a perspectiva da educação musical, as atividades propostas promoveram aprendizagem sobre a diversidade de gêneros e tipos de instrumentos musicais, compositores e intérpretes. Os discentes tiveram a oportunidade de experienciar o prazer que se situa no ato de fazer Música: cantar, tocar, aprender letras de canções, interpretar. Estes saberes foram situados historicamente, como fundamento para o processo de construção das identidades e de valorização das culturas, da memória oral dos diferentes povos.

Nesse sentido, não foi difícil se deparar com alunos que tivessem uma casa de farinha na família ou fossem filho, neto ou sobrinho de uma baiana de acarajé. Estes vínculos, normalmente, proporcionavam uma relação afetiva e íntima com o tema, ampliando a motivação e o envolvimento das crianças para as atividades das aulas de Música, aspectos estes que influenciaram positivamente as práticas de ensino.

O trabalho com temas voltados às tradições culturais impactou diretamente no sentimento de pertencimento e na elaboração das identidades dos alunos, ressignificando e desmistificando certos equívocos dos conhecimentos herdados através dos tempos, de forma descolonizada e imoderada. Portanto, é oportuno destacar a necessidade de estudos mais aprofundados sobre esse campo de atuação do professor de Música em face da relevância social do tema e da possibilidade de ampliação dos conhecimentos sobre o ensino de Música em contextos hospitalares. 


\section{REFERÊNCIAS}

CASCUDO, L. C. Civilização e cultura: pesquisas e notas de etnografia geral. 1a ed. São Paulo: Global, 2004.

. Literatura Oral no Brasil. 2a ed. São Paulo: Global, 2006

. Tradição, ciência do povo: pesquisas na cultura popular do Brasil. 2a ed. São Paulo: Global, 2013.

FONSECA, E. S. Atendimento escolar no ambiente hospitalar. São Paulo: Memnon, 2008

FORQUIN, J. C. Escola e Cultura: as bases sociais e epistemológicas do conhecimento escolar. Porto Alegre: Artes Médicas Sul, 1993.

RODRIGUES, J. M. C. Classes hospitalares: o espaço pedagógico nas unidades de saúde. Rio de Janeiro: Wak Editora, 2012.

LEAHY, R. C. As Ganhadeiras de Itapuã: memória e identidade em performance. Plural Pluriel, n. 17, Consulté à l'adresse. Disponível em: https://www.pluralpluriel.org/index.php/revue/article/ view/126. Acesso em: 28 de agosto de 2019.

PRANDI, R. De africano a afro-brasileiro: etnia, identidade, religião. Revista USP, São Paulo, n. 46, p. 52-65, jun./ago, 2000.

RELEASE. Ganhadeiras de Itapuã. Salvador, 2019 Disponível em: http://ganhadeirasdeitapua.blogspot.com/p/historia.html. Acesso em: 20 de março de 2020. 